\title{
Democracia interna de los partidos políticos. Tres casos de la práctica judicial
}

\section{María del Pilar Hernández*}

* Investigadora en el Instituto de Investigaciones Jurídicas de la UNAM. Correo electrónico:mphm.iij@gmail.com. 
1. La apertura al conocimiento de eventuales omisiones, defectos o contradicciones en los documentos básicos de los partidos, manifestación de su potestad autorregulativa y autoorganizativa que irremediablemente acarreaban lesión a la esfera de derechos políticos-electorales de sus militantes y afiliados, es muy reciente, data de $2003,{ }^{1}$ año en que se da un periplo al criterio sostenido por la Sala Superior, tornando procedente el juicio para la protección de los derechos políticos electorales de los ciudadanos de manera directa en contra de los actos definitivos e irreparables de tales entidades de interés público que, hasta ese momento, habían escapado a todo tipo de control jurisdiccional en la especie.

2. Si bien los actos lesivos de derechos políticos electorales sentaron la primera escalada hacia el control jurisdiccional de las entidades partidarias, el propio Tribunal Electoral del Poder Judicial de la Federación (TEPJF) afinó su competencia en materia de control concreto de las normas generales autoimpuestas, que representan los propios documentos básicos de los partidos políticos, reconociendo plenamente su autonomía interna partidaria, regulatoria y organizativa, siempre en total apego a las normas constitucionales y legales, al principio democrático, así como al respeto de los derechos fundamentales consustanciales al de asociación.

3. El cambio de marco constitucional y legal que se verificó, respectivamente, en 2007 y 2008, sistematizó y asumió tanto los reclamos de los actores políticos, como la labor jurisprudencial que en materia partidaria y en particular de su vida interna, se había generado por el TEPJF, tornando el régimen normativo de las entidades de interés público más sistemático, coherente y consistente. Más allá de la expresa prescripción constitucional contenida en el artículo 41, fracción I, párrafo tercero, en el sentido de que "Las autoridades electorales solamente podrán intervenir en los asuntos internos de los partido políticos en los términos que señalan esta Constitución y la ley"; el Cofipe contiene todo un libro dedicado a los partidos políticos que se ha erigido, al lado de las normas, principios y valores constitucionales, en el marco resolutorio e interpretativo de la salas Superior y regionales, en particular, de los dos temas que aquí se analizan.

1 Tesis S3ELJ 03/2003 con el rubro: JUICIO PARA LA PROTECCIÓN DE LOS DERECHOS político-electorales del CiUdadano. Procede Contra aCtos Definitivos E irrePARABLES DE LOS PARTIDOS POLÍ́TICOS. 
4. El camino transitado en clave de la selección interna, bien de candidatos a cargos de dirigencia intrapartidaria, o en lo que hace a los de elección popular que son susceptibles de ser modificados jurisdiccionalmente cuando se trata de violaciones estatutarias, exige una reflexión previa en relación con los estatutos.

5. En vía de principio la dual naturaleza de los partidos que se evidencia en su también doble regulación, desde el ámbito del derecho privado - el asociacionista contemplado en el artículo 9o. de la Constitución (CPEUM) - y del derecho público contenido en el artículo 41 fracción I, segundo párrafo, su carácter de entidad de interés público y sus consecuentes funciones de promover la vida democrática, la integración de la representación nacional y el acceso de los ciudadanos al ejercicio del poder público, lo cual justifica que sean sujetos de prerrogativas y subvenciones por parte del Estado, y que su regulación se lleve a cabo mediante normas de derecho público, perfila ya lo difícil del control jurídico que sobre ellos se concreta y, en consecuencia, de la caracterización de su propio régimen estatutario. ${ }^{2}$ Esto es así, en virtud del olvido del papel que juegan las entidades partidarias en tanto asociaciones de ciudadanos y su trascendente papel en la formación de la voluntad general del Estado que se concreta en el momento de verificar el principio democrático vía la renovación periódica de los órganos de representación, a través del sufragio universal, libre, secreto y directo, esto es, son órganos de relevancia constitucional que vinculan al ciudadano con el Estado.

6. En un ejercicio de sistematicidad, coherencia y consistencia de lo que implica el orden jurídico y sus principios, habríamos de admitir, tal como lo hemos dejado asentado líneas arriba (supra \$3-6), que el principio democrático en su manifestación global-general y globalsectorial, tanto en su sentido material, como estructural se proyectan en los estatutos de los partidos políticos, inter alia, como:

a) La primera manifestación de la libertad política que se encuentra en la base de dichas organizaciones.

b) Ad intra de las entidades partidarias, como el primer cuerpo de normas generales de mayor relevancia, en donde se denota su propia estructura organizativa y funcional, id est, se erigen en el con-

2 La Sala Superior ha señalado que "los partidos políticos están elevados constitucionalmente al rango de entidades de interés público, en razón de las importantes actividades que la Carta Magna les confiere". Cfr. "Medios de Defensa internos De los Partidos". 
junto de normas regulatorias del régimen de su organización, en donde se establecen los derechos, deberes, régimen disciplinario, sanciones y en general, la estructura orgánica de la misma. Se erigen en un ordenamiento parcial de cara al global que es el orden jurídico total. ${ }^{3}$

La anterior consideración permite, en términos de la referida interpretación constitucional por el principio democrático, la verificación de eventuales contradicciones entre tales normas estatutarias y los imperativos previstos constitucional y legalmente respecto de los partidos políticos; normas que en la verificación de la regularidad constitucional o legal permiten evidenciar eventuales estructuras verticalistas de dirección y de toma de decisiones, mediante las cuales se limitaría irrazonablemente el derecho a la participación política de los miembros o, en su caso, de libertad de expresión si en lo particular, existiera algún dispositivo que prohibiese la formación de corrientes al interior del partido, eventos éstos que, obvio, contrarían el principio democrático material y sustancial, rindiéndoles inconstitucionales en virtud de la inobservancia de aquella que impone para los partidos políticos una estructura democrática.

c) Representan una prerrogativa que se enlaza con la libertad para asociarse con fines políticos que sugiere la existencia de un ámbito de autodeterminación propio que se ejerce, en aras de la legitimidad democrática, por el órgano jerárquicamente más relevante y representativo: la Asamblea Nacional o su equivalente.

d) Tales documentos adquieren la naturaleza de normas generales autoimpuestas, que en razón de su contenido y los fines a los que se enderezan adquieren una diferencia específica y un rango superior al de otras asociaciones. ${ }^{4} \mathrm{Al}$ decir de Pacheco: "Estas normas son jurídicas y contienen (sic) prescripciones normativas de alcance limitado a los miembros de la corporación, destinadas a regular la organización, actividad y vida interna de la institución, y las relaciones entre los miembros de la misma”, el autor continúa con la afirmación de que el estatuto es "un conjunto de normas

3 Kelsen, Hans, Teoría general del derecho y del Estado, 2a. ed., México, UNAM, 1958, p. 117.

4 "Medios de defensa internos de los partidos políticos. Se deben agotar PARA CUMPLIR EL PRINCIPIO DE DEFINITIVIDAD", Tesis S3ELJ 04/2003, Sala Superior, RJE 2004, núm. 7, pp. 20-22. 
jurídicas... de carácter general, abstracto y permanente para los miembros de la corporación". ${ }^{5}$

7. El fundamento constitucional y de validez de los estatutos partidarios y su estricto apego a la observancia del principio democrático derivan de la vinculación armónica de lo dispuesto en el artículo 41, fracción I, segundo párrafo, y el artículo 23 y 22.5 del Cofipe, por lo que hace al asidero constitucional se determina que los fines y funciones supra indicadas $(\$ 13)$; habrán de ser concretados por las entidades partidarias de acuerdo con los programas, principios e ideas que postula; por lo que hace al fundamento legal el artículo $23.1 \mathrm{del}$ Cofipe prescribe claramente que las organizaciones partidarias para el logro de sus fines constitucionales ajustarán su conducta a las disposiciones establecidas, precisamente en ese cuerpo legal electoral. No omito referir la expresa referencia al artículo 22.5 que dispone el ámbito de autonomía interna organizativa y regulatoria de los partidos políticos, vía los multicitados documentos básicos y conforme a lo dispuesto en el propio cuerpo normativo ordinario.

8. En el caso de mérito, vale indicar que es el artículo 27 del Cofipe el que enuncia los contenidos mínimos que habrán de contener los estatutos, los cuales, en forma alguna, se entienden como limitativos de la autonomía interna, tal como lo ha dispuesto el propio TEPJF, ${ }^{6}$ al sostener que dicho precepto no contiene:

Un entero y acabado desarrollo de los aspectos declarativos, ideológicos, programáticos, orgánicos, procedimentales y sustantivos porque se suprimiría o limitaría indebidamente esa libertad auto-organizativa para el ejercicio del derecho de asociación en materia político-electoral que se establece en favor de los ciudadanos.

9. En vía de principio y en la línea argumentativa que ha sentado César Astudillo, ${ }^{7}$ el tipo de control constitucional que el TEPJF ve-

5 Italia, Vittorio, "Statuto in generale", Enciclopedia del Diritto, Milano, Giuffrè Editore, Vol. XLIII, pp. 977 y ss.

6 "Estatutos de los Partidos políticos. El Control de SU CONSTITUCiOnAlidad Y LEGALIDAD DEBE ARMONIZAR EL DERECHO DE ASOCIACIÓN DE LOS CIUDADANOS Y LA LiberTAD DE AUTOORGANizACión DE LOS Institutos Políticos”, Tesis S3EL008/2005, Sala Superior, COJTR 1997-2005,

7 "La inconstitucionalidad del artículo 94 de los estatutos del Partido Acción Nacional", Comentarios a las Sentencias del Tribunal Electoral del Poder Judicial de la Federación, México, TEPJF, 2008, núm. 8, pp. 132 y ss. 
rifica cuando se trata de la democracia interna es de tipo concreto, esto es, que se conoce con motivo de su aplicación, así, el órgano jurisdiccional toma conocimiento de la norma jurídica por los efectos concretos que produce en la esfera del ciudadano una vez que se ha aplicado a un supuesto determinado. Es un control que se endereza a proteger los derechos subjetivos de las personas, ${ }^{8}$ al caso vía el juicio para la protección de los derechos político-electorales del ciudadano (JDC). Así lo ha reconocido el propio Tribunal al determinar que:

Los actos de autoridad que se encuentren vinculados con la regulación estatutaria, en cuanto a su reconocimiento y aplicación, mediante la formulación de los agravios encaminados a la demostración de la ilegalidad o inconstitucionalidad de los dispositivos de normatividad interna que se combatan, siempre y cuando se promuevan o interpongan tales procesos por quienes tengan legitimación e interés jurídico respecto al acto o resolución concretos de que se trate. ${ }^{9}$

10. Tal control concreto ha posibilitado al TEPJF, entrar al conocimiento y control jurisdiccional de la autonomía organizativa en tratándose de selección interna de candidatos y consecuentemente, de la modificación de las decisiones intrapartidarias.

11. El asunto identificado bajo el indicativo SUP-JDC 51/2007, que se emite con motivo de la impugnación que se enderezó en contra de los actos de la dirigencia partidaria en el proceso interno de elección de candidatos de presidente del Comité Directivo del Partido Acción Nacional en el estado de Hidalgo, apunta dos aspectos fundamentales a saber: a) La necesaria fundamentación legal de los actos de las autoridades intrapartidarias (Cofipe, Estatutos Generales y Reglamento de Elecciones Estatales y Municipales de Acción Nacional), y b) la certeza jurídica conferida a la militancia partidaria de verse debidamente representada por las autoridades electas democráticamente.

12. SUP-JDC 498/2009, se impugna la dilación de la justicia intrapartidaria así como la resolución confirmatoria de la triunfante en el proceso interno de selección de candidatos y candidatas a cargos de

8 "La impugnación del contenido de los estatutos de los partidos políticos nacionales no se puede hacer de manera directa, mediante el ejercicio de alguna acción o la interposición de algún medio de impugnación, en que la parte equivalente a una demandada o a una autoridad responsable, sea directamente el partido político titular de los estatutos".

9 "Estatutos de Un PARTido político o DE UNA COAlición. Hipótesis DE IMPUGNACIÓN”, S3ELJ55/2002, Sala Superior, COJTR 1997-2005, pp. 124 y 125. 
elección popular que verifica el Tribunal Electoral del Distrito Federal así como la defectuosa valoración de las causales de nulidad de la votación, el TEPJF declara la nulidad de 47 casillas y otorga el triunfo a la impugnante, permitiéndole contender en las elecciones para jefe de demarcación territorial de Iztapalapa.

13. La resolución identificada bajo las siglas y números SUP-JDC $12 / 210$, restituye sus derechos de militante del PAN, el que como resultado de un proceso disciplinario e imposición de sanción por haber sido postulado por el PVEM a una candidatura suplente a diputado local, fue expulsado de la delegación de Nayarit. La Sala Superior aprecia que la resolución de expulsión no es conforme a derecho, toda vez que no fueron valoradas órgano de justicia interpartidaria a cabalidad $y$, en consecuencia, revoca la resolución sancionatoria de expulsión emitida por la delegación estatal del PAN.

14. Mediante la resolución de expediente SUP-JDC 1010/2010, la Sala Superior conoció de la impugnación dirigida en contra de la Convocatoria para la elección de candidatos o candidatas a gobernador del estado de Guerrero para el proceso electoral 2011 y el acuerdo por el cual la Comisión Nacional Electoral del PRD realizó observaciones a aquélla (ACU-CNE-370/2010, convalidándola), toda vez que al tiempo de la convocatoria se estableció un método de selección de aspirantes (aplicación de encuestas, presentación de programa de gobierno, ante tres académicos y participación de un colegio electoral integrado por militantes distinguidos, cada uno con un valor porcentual), la Sala Superior revocó el indicado acuerdo por considerar que los métodos ahí incluidos no se apegaba a los procedimientos previstos por las normas estatutarias y el propio Reglamento de Elecciones y Consultas del PRD; previéndose en éste la elección de los aspirantes por parte de los delegados mediante sufragio directo y secreto.

15. El control de la regularidad constitucionalidad de los estatutos partidistas se verifica por parte del TEPJF de manera indirecta tal como lo ha reconocido el máximo órgano central de potestad jurisdiccional electoral, así:

La impugnación del contenido de los estatutos de los partidos políticos nacionales no se puede hacer de manera directa, mediante el ejercicio de alguna acción o la interposición de algún medio de impugnación, en que 
la parte equivalente a una demandada o a una autoridad responsable, sea directamente el partido político titular de los estatutos. ${ }^{10}$

Ante tal hecho, la misma Sala ha reconocido que el control indirecto de la regularidad constitucional estatutaria se podrá verificar si

los actos de autoridad que se encuentren vinculados con la regulación estatutaria, en cuanto a su reconocimiento y aplicación, mediante la formulación de los agravios encaminados a la demostración de la ilegalidad o inconstitucionalidad de los dispositivos de normatividad interna que se combatan, siempre y cuando se promuevan o interpongan tales procesos por quienes tengan legitimación e interés jurídico respecto al acto o resolución concretos de que se trate. ${ }^{11}$

16. César Astudillo ${ }^{12}$ ha realizado un estudio sistemático de los supuestos de control constitucional estatuario que la Sala Superior ha ido construyendo y que me permito reproducir ad litera, así:

a) Los estatutos pueden impugnarse cuando se estime que el texto original presentado ante el Consejo General del IFE, se encuentra viciado de inconstitucionalidad o ilegalidad. La impugnación procede una vez que el propio IFE haya considerado, expresa o tácitamente la conformidad constitucional y legal de los estatutos, $y$ haya otorgado, en consecuencia, el registro como partido político nacional a la organización solicitante o a la coalición respectiva.

b) Cuando se considere que los vicios de inconstitucionalidad o ilegalidad derivan de una modificación posterior a los estatutos. El control procede, igualmente, una vez que las modificaciones hayan sido comunicadas al Consejo General del IFE y que éste haya declarado su procedencia constitucional y legal.

c) En el momento en que la autoridad electoral emita un acto o resolución, cuyo contenido o sentido reconozca, como base fundamental de sustentación, a las normas estatutarias que se conside-

10 "Emblema de Un PARTido político o COALICIÓN. LA IMPUGNaCión DE SUS COLORES IMPLICA LA DE SUS ESTATUtOs”, S3EL 061/2002, Sala Superior, COJTR 1997-2005, pp. 538-540.

11 "Estatutos de un partido político o de una COAlición. Hipótesis De impugNACIÓN”, S3ELJ55/2002, Sala Superior, COJTR 1997-2005, pp. 124 y 125.

12 Op. cit., p. 135. 
ran inconstitucionales o ilegales, o fueran efectos o consecuencias directas de ellas.

17. Se inscribe en el tercer supuesto la sentencia de la Sala Superior (SUP-JDC 2638/2008 y JDC-SUP 2639 Acumulados) mediante la cual decreta la inconstitucionalidad de los estatutos del Partido del Trabajo (PT), y la consecuente revocación del VII Congreso Nacional Ordinario del $\mathrm{PT}$, como todos y cada uno de los actos relacionados, incluidos la convocatoria, los acuerdos y resolutivos adoptados en el mismo y que se emitieron con fundamento en los referidos estatutos. Sobreviene la inconstitucionalidad en virtud que se verifica de su contenido antidemocrático, toda vez que no garantizaban la celebración de elecciones de su dirigencia conforme a los principios de legalidad, igualdad, libertad, certeza, objetividad e imparcialidad; la inexistencia de un órgano estatutario garante del desarrollo de los procesos internos; la permisión de la reelección indefinida de la dirigencia que atenta contra los derechos políticos-electorales de la militancia (asociación, votar y ser votados para ocupar cargos de dirigencia); inexistencia de cusas de incompatibilidad; voto por aclamación contrario al principio democrático y a las características del sufragio (universal, libre, directo y secreto).

18. A la sazón de las reformas constitucionales y legales verificadas en 2007 y 2008, respectivamente, la máxima jurisdicción en materia electoral ha sentado una serie de criterios que permiten visualizar en perspectiva y prospectiva, el quehacer que en la materia dicho órgano ha venido desarrollando y que evidencia la trascendencia en la concreción del principio democrático material. Veamos los casos.

19. Como bien lo señala José de Jesús Orozco Henríquez ${ }^{13}$ la totalidad de los ordenamientos constitucionales y/o legales prevén, en forma explícita o implícita, que los tribunales (electorales y/o, en su caso, constitucionales u ordinarios), conozcan de impugnaciones respecto de actos de partidos políticos relacionados con su democracia interna, por la presunta violación del derecho político-electoral de sus afiliados, ya sea en forma directa, donde se combata determinado acto interno partidario, y/o indirecta, a través del acto de autoridad

13 "La democracia interna de los partidos políticos en Iberoamérica y su garantía jurisdiccional", VIII Congreso Iberoamericano de Derecho Constitucional, Sevilla, España, 2003, http://congreso.us.es/cidc/Ponencias/electoral/jesusOROZCO.pdf, consultado el 12 de diciembre de 2010. 
administrativa electoral que se base, convalide $u$ otorgue eficacia al respectivo acto partidario.

20. En principio, como se ha dejado en plena expresión, el mecanismo jurisdiccional que ha tornado eficaces los derechos políticoselectorales del ciudadano mexicano, en general, y de la militancia, en particular, es el juicio para la protección de los derechos políticos electorales del ciudadano (JDC). Dicho recurso ha evidenciado su capacidad restauradora por lo que hace a los derechos que se enderezan a concretar la democracia intrapartidaria e, inopinadamente, se determina como aquel que de manera directa o indirecta posibilita en el goce pleno de los derechos públicos subjetivos al interior de la entidad partidaria (trátese de sufragio, cargos de designación, afiliación, expresión, inter alia) y, en su caso, el control concreto de constitucionalidad de los estatutos.

21. Por lo que hace a la eficacia de los derechos de la militancia y la observancia plena de las normas estatutarias es de mencionar el asunto identificado bajo las siglas y números SUP-JDC-51/2007, en el que la Sala Superior resuelve revocar la resolución de las autoridades partidarias consistente en la expulsión ilegal de un militante, esto es así porque en estricto derecho una expulsión sin apego al principio de legalidad afecta otros derechos como en el caso concreto, el dejar a salvo el diverso para contender bien para un cargo interno ya para uno de naturaleza electiva.

22. Precisamente cuando se trata de cargos electivos, el SUPJDC-498/2009, la Sala Superior después de un pormenorizado análisis decidió la nulidad de votación de algunas casillas, lo cual llevó a la recomposición del cómputo y, en consecuencia, al cambio de posición en el triunfo de la candidata que en sede local (Tribunal Electoral del Distrito Federal) así se había declarado.

23. La fuerza restauradora del JDC llega a tal grado que permite actualizar de esa forma una elección que, de no existir el mecanismo, perpetraría una flagrante violación de derechos fundamentales. El caso es de verdadera trascendencia toda vez que en el conocimiento de la Sala Superior, particularmente de la ponencia del magistrado Pedro Esteban Penagos, se corrigieron errores aritméticos que en la más estricta racionalidad numérica no fueron aceptables, más allá de las múltiples irregularidades en la integración de las casillas receptoras de votación, completamente fuera del marco de las normas estatutarias del Partido de la Revolución Democrática. 
24. Vía en conocimiento del SUP-JDC-1010/2010, el magistrado Flavio Galván Rivera, conoce de la impugnación en contra del ACUCNE-370/2010 (Acuerdo) al cual se encontraba anexa la "Convocatoria para la elección de candidatos o candidatas del Partido de la Revolución Democrática a Gobernador del Estado Libre y Soberano de Guerrero para el proceso local ordinario de 2011", toda vez que se puso en evidencia su total exceso de exigencias y previsiones que en forma alguna ni el estatuto ni el denominado Reglamento General de Elecciones y Consultas del Partido de la Revolución Democrática prevén cuando se trata de la renovación de sus dirigencias estatales, actos todos ellos que fueron convalidados por la entonces dirigencia estatal del estado de Guerrero.

25. Control distinto despliega el juicio para la protección de los derechos políticos electorales, cuando se analiza el asunto SUPJDC-12/2010, mediante el que se combatió la aplicación de medidas disciplinarias a un militante del Partido Acción Nacional, al cual de manera indebida la delegación estatal de Nayarit del Partido Acción Nacional le expulsa por haber participado "indebidamente" como candidato del Partido Verde Ecologista de México, sin autorización previa de la dirigencia partidaria. En este caso, ante la defectuosa valoración que el órgano estatal realizó de los elementos que avalaban la expulsión sin considerar en ningún momento la ausencia de voluntad (autorización expresa del militante), la Sala Superior en ejercicio de su plena jurisdicción, procede a revocar la resolución restituyendo al afiliado en el pleno goce y ejercicio de sus derechos.

26. Finalmente, por lo que hace al control de la normativa estatutaria que como se ha indicado líneas arriba, es de control indirecto, evitamos repetirnos en este sentido, así:

27. Son de traer a la memoria aquellos dos asuntos a través de los cuales se sentaron los denominados elementos mínimos que, a juicio de los entonces integrantes de la Sala Superior, debían contener los estatutos de los partidos políticos (SUP-JDC-781/2002 y SUPJDC-021/2002), siendo de recibo en este caso el último indicado, y mediante el cual la multicitada Sala Superior resolvió que eran ilegales diversos artículos de los estatutos de un partido político que, no obstante haber sido aprobados con anterioridad por la autoridad electoral administrativa, no se ajustaban a los requisitos de establecer "procedimientos democráticos para la integración y renovación de los órganos directivos" del partido, así como el derecho de los afiliados de 
"participar personalmente o por medio de delegados en asambleas y convenciones, y el de poder ser integrante de los órganos directivos", razón por la cual concedió al respectivo partido político un plazo para modificar sus estatutos y una vez aprobados por la autoridad electoral en cuanto a su constitucionalidad y legalidad, proceder a renovar su dirigencia con base en la nueva normativa partidaria.

28. Regresando al presente, en el asunto identificado por sus siglas y números SUP-JDC-2638 y acumulado 2639, se decreta la inconstitucionalidad de los estatutos del PT y la consecuente revocación del VII Congreso Nacional Ordinario del PT, así como todos y cada uno de los actos relacionados, incluidos la convocatoria, los acuerdos y resolutivos adoptados en el mismo y que se emitieron con fundamento en los referidos estatutos. Sobreviene la inconstitucionalidad en virtud de que se verifica su contenido antidemocrático, toda vez que no garantizaban la celebración de elecciones de su dirigencia conforme a los principios de legalidad, igualdad, libertad, certeza, objetividad e imparcialidad; la inexistencia de un órgano estatutario garante del desarrollo de los procesos internos; la permisión de la reelección indefinida de la dirigencia que atenta contra los derechos políticos-electorales de la militancia (asociación, votar y ser votados para ocupar cargos de dirigencia); inexistencia de causas de incompatibilidad; voto por aclamación contrario al principio democrático y a las características del sufragio (universal, libre, directo y secreto).

\section{Conclusiones}

Resulta por demás inopinado el hecho de que en el transcurso de la vida del Tribunal Electoral del Poder Judicial de la Federación, es hasta los últimos 10 años que más allá de la paulatina transformación del régimen constitucional y legal del régimen de los partidos políticos, es virtud la labor interpretativa de tal órgano constitucional que la democracia interna de los partidos políticos sea en clave autonomía normativa, ya organizativa admite nuevos estándares de racionalidad.

Lo anterior es de recepción en el máximo órgano jurisdiccional, virtud los esquemas de control de la regularidad constitucional concreta que ha ido integrando, amén de la renovada visión de una interpretación constitucional y desde luego, legal a través de principios. Labor que incuestionablemente irá en avance dada la competencia que ahora le ha sido asignada en tanto órgano de control constitucional en materia electoral. 